\title{
Motivasi Kerja melalui Gaya Kepemimpinan pada Bimbingan dan Konsultasi Belajar Nurul Fikri Jakarta Selatan
}

\author{
Wiwik Widiyanti ${ }^{1}$, Isnurrini Hidayat Susilowati ${ }^{2}$, Julia Retnowulan ${ }^{3}$ Iman Wahyudi $^{4}$ \\ ${ }^{1}$ Universitas Binas Sarana Informatika/Fakultas Ekonomi dan Bisnis \\ e-mail: wiwik.www@bsi.ac.id \\ ${ }^{2}$ Universitas Binas Sarana Informatika/Fakultas Ekonomi dan Bisnis \\ e-mail: isnurrini.ihs@bsi.ac.id \\ ${ }^{3}$ Universitas Binas Sarana Informatika/Fakultas Ekonomi dan Bisnis \\ e-mail: julia.jlr@bsi.ac.id \\ ${ }^{4}$ Universitas Binas Sarana Informatika/Fakultas Ekonomi dan Bisnis \\ e-mail: imanwhyd@gmail.com
}
Cara Sitasi: Widiyanti, W., Hidayat, I., Susilowati, Retnowulan, J., \& Wahyudi, I. (2019). Motivasi Kerja melalui Gaya Kepemimpinan pada Bimbingan dan Konsultasi Belajar Nurul Fikri Jakarta Selatan. Widya Cipta, 3(1), 35-42.

\begin{abstract}
The activity of a company requires quality human resources. Humans are a resource factor that is different from other resources because humans are creatures that have strong feelings and desires. Therefore, human resources must be able to be fostered and managed effectively and efficiently in order to provide optimal results for the company. Relationship patterns that occur between superiors and employees are strongly influenced by leadership style, is one of the factors that influence the behavior of others to work and strive to achieve company goals, because the success of an organization is very dependent on the effectiveness of the company. This study aims to determine the effect of leadership style on employee work motivation Guidance and Learning Consultation Nurul Fikri Ragunan. In this study, the number of respondents was 40 employees. Data was collected using a questionnaire with data analysis using a normality test, linearity test, simple regression analysis, t-test, correlation coefficient, and coefficient of determination. The results of the study showed leadership style towards employee work motivation Guidance and Learning Consultation Nurul Fikri Ragunan. The magnitude of the correlation coefficient shows the amount of 0.754, it means that the relationship between organizational culture and employee performance is quite strong. The coefficient of determination or $R$ Squared $=0.568$ which means that the organizational culture has a contribution to employee performance by $43.2 \%$ while the rest is influenced by factors other than leadership style.
\end{abstract}

Keywords: Leadership Style, Motivation of Employee Work

\section{PENDAHULUAN}

Aktivitas sebuah perusahaan membutuhkan sumber daya manusia yang berkualitas. Manusia merupakan faktor sumber daya yang berbeda dengan sumberdaya lainnya, sebab manusia adalah makhluk yang memiliki perasaan dan keinginan yang kuat. Oleh karena itu, sumber daya manusia harus dapat dibina dan dikelola secara efektif dan efisien agar dapat memberikan hasil yang optimal bagi perusahaan.

Peranan atasan atau yang biasa disebut seorang pimpinan sangatlah besar bagi keberhasilan suatu perusahaan dalam mencapai tujuan. Dari mereka muncul ide dan gagasan-gagasan baru yang inovatif dalam perkembangan perusahaan, namun bawahan juga memiliki peranan yang tidak kalah penting, karena bawahan inilah yang akan menjalankan dan melaksanakan gagasan pemimpin yang tertuang dalam setiap keputusan.

Oleh karena itu dibutuhkan seorang pemimpin yang mampu memotivasi dan mengkoordinasikan karyawan dengan cara mempengaruhi perilaku agar menjalankan dan membuat iklim kerja yang kondusif (Fauzen, 2014).

Pola hubungan yang terjadi antara atasan dengan karyawan sangat dipengaruhi oleh gaya kepemimpinan, merupakan salah satu faktor yang 
mempengaruhi prilaku orang lain untuk bekerja dan berupaya dalam mencapai tujuan perusahaan, karena keberhasilan suatu organisasi sangat tergantung pada efektifitas yang terdapat diperusahaan. Dalam kenyataannya, tidak semua pemimpin berprilaku baik atau mampu menciptakan iklim atau suasana kerja yang kondusif dan kekeluargaan, banyak dijumpai pimpinan dalam kepemimpinannya bersikap egois, tidak mau bersifat kooperatif, tidak mau berkorban dan tidak mau memberikan dorongan semangat kepada para karyawannya, biasanya menyebabkan perasaan tidak senang karyawan terhadap atasan yang diwujudkan dalam bentuk sifat yang bermalasmalasan.

Pentingnya motivasi untuk memberikan refleksi kepada para karyawannya dengan melakukan dorongan, agar para karyawan dapat bekerja sejalan dengan batasan yang telah ditentukan guna mencapai suatu tujuan yang optimal. Pengertian proses pemberian dorongan tersebut adalah serangkaian aktivitas yang harus dilalui atau dilakukan untuk menumbuhkan dorongan kepada karyawannya untuk bekerja sesuai dengan tujuan organisasi dalam memotivasi karyawan. pemimpin harus mengetahui apa yang dibutuhkan oleh seorang karyawan agar termotivasi untuk dapat bekerja dengan baik dapat dikatakan bahwa dari mutu gaya kepemimpinan akan memainkan peran penting didalam memotivasi kerja karyawan hal tersebut dapat terlihat dari peningkatan motivasi kerja pada saat mengikuti serangkaian kegiatan.

Banyak penelitian yang mengambil tema mengenai gaya kepemimpinan salah satunya adalah penelitian gaya kepemimpinan $(\mathrm{X})$ terhadap kinerja karyawan (Y) pada Perpustakan UB. Dari penelitian tersebut diperoleh hasil bahwa secara bersama-sama semua variabel (X) mempunyai pengaruh pada kinerja karyawan. Pemimpin yang direktif memiliki pengaruh secara sendiri-sendiri pada kinerja karyawan, sedangkan pemimpin suportif dan partisipatif tidak mempengaruhi kinerja karyawan di Perpustakaan UB (Khairizah et al., 2015).

Lain halnya dengan penelitian dengan tema gaya kepemimpinan dengan hasil penelitian menunjukkan bahwa gaya kepemimpinan mempunyai pengaruh positif dan signifikan 5\% terhadap kinerja karyawan, dengan koefisien determinasi sebesar $69 \%$ dimana kinerja karyawan dipengaruhi olah gaya kepemimpinan. Sementara sisanya $31 \%$ dipengaruhi oleh variabel-variabel lain di luar variabel yang diteliti misalnya variabel individu (Muizu, Irfan, \& Kaltum, 2017).

Bimbingan Belajar dan Konseling Nurul Fikri merupakan suatu perusahaan yang bergerak dalam bidang pendidikan dan mempunyai banyak cabang. Di setiap cabang dipimpin oleh seorang manajer wilayah yang membawahi staf pengajar dan staf admin. Kedua staf tersebut harus saling bersinergi dengan harmonis agar aktivitas Bimbingan Belajar dan Konseling berjalan dengan lancar. Oleh karena itu dibutuhkan gaya kepemimpinan yang tepat untuk bisa memotivasi karyawan agar tercapai tujuan yang diinginkan bersama.

Permasalahan yang terjadi pada Bimbingan Belajar dan Konsultasi Nurul Fikri Ragunan Jakarta Selatan ini adalah belum ditemukannya gaya kepemimpinan yang pas untuk memotivasi karyawan guna mencapai tujuan bersama.

Tujuan dari penelitian ini adalah untuk mengetahui seberapa besar pengaruh gaya kepemimpinan terhadap motivasi kerja karyawan dan juga menganalisa gaya kepemimpinan yang sebaiknya diterapkan pada Bimbingan Belajar Nurul Fikri Ragunan Jakarta Selatan.

Seorang pemimpin sudah seharusnya mempunyai jiwa kepemimpinan. Kepemimpinan adalah kemampuan untuk memengaruhi kelompok menuju pencapaian sasaran (Robbins \& Judge, 2015). Pada teori yang lain menyebutkan bahwa kepemimpinan adalah kemampuan untuk memberikan pengaruh yang konstruktif kepada orang lain untuk melakukan suatu usaha kooperatif mencapai tujuan yang sudah direncanakan (Kartono \& Kartini, 2014). Hal ini bisa disimpulkan bahwa kepemimpinan adalah tindakan seorang pemimpin secara menyeluruh dalam mempengaruhi kelompok untuk menuju suatu pencapaian atau tujuan organisasi.

Ada beberapa tindakan seorang pemimpin yang seharusnya dilakukan menurut (Tead, 2004) dalam pemberian perintah. Perintah biasanya sudah tercakup dalam tugas, kewajiban, dan tanggung jawab yang harus dilakukan oleh setiap individu anggota kelompok.

1. Pemberian celaan atau pujian

Celaan harus diberikan secara objektif dan tidak bersifat subjektif, juga tidak disertai emosiemosi yang negatif dan sebaiknya berupa teguran, dan dilakukan secara rahasia. Sebaliknya pujian supaya diberikan, sebab pribadi yang bersangkutan telah melakukan tugasnya dengan baik, dan mampu berprestasi.

3. Tingkah laku pribadi yang benar

Pemimpin harus bersifat objektif dan jujur. Ia juga harus menjauhkan diri dari rasa pilih kasih atau favoritisme.

4. Peka terhadap saran-saran

Sifat pemimpin itu harus luwes dan terbuka, dan peka pada saran-saran eksternal yang positif sifatnya. Dia harus menghargai pendapatpendapat orang lain, untuk kemudian mengombinasikanya dengan ide-ide sendiri. Dengan begitu dia bisa membangkitkan inisiatif 
anggota masyarakat untuk memberikan saransaran yang baik.

5. Memperkuat rasa kesatuan kelompok.

Tim kerja merupakan kunci untuk menuju operasi yang sukses, diawali mulai unit terkecil hingga yang terbesar harus menjadi satu kesatuan hingga memiliki satu visi dan misi yang pada akhirnya akan mempermudah pencapaian tujuan yang diingikan.

6. Mengembangkan rasa tanggung jawab di masyarakat.

Penyampaian kekuasaan yang disertai dengan pertanggung jawaban akan mengembangkan rasa kepercayaan bersama dan rasa hormat diantara yang dipimpin dan yang memimpin.

7. Membuat putusan yang bernilai tepat pada waktunya

Seorang pemimpin harus mempunyai kemampuan dalam ramalan yang cepat dari situasi-situasi sampai pada keputusan yang bernilai. Seorang pemimpin harus dapat berpikir logis pada keadaan yang sangat gawat dan memutuskan dengan cepat suatu tindakan yang diperlukan untuk mengambil kesempatan yang ada pada waktu itu.

Ada empat gaya kepemimpinan antara lain (Suwatno \& Priansa, 2014) :

1. Direktif artinya pemimpin melakukan sesuatu agar karyawan tahu apa yang diharapkan pimpinan ini dari mereka, membuat jadwal kerja, dan memberi arahan khusus mengenai bagaimana menyelesaikan tugas.

2. Mendukung yang artinya pemimpin seperti ini mempunyai ramah dan pedulian pada karyawan.

3. Partisipatif merupakan suatu hal yang dilakukan pemimpin dalam membuat keputusan yaitu dengan terlebih dahulu konsultasi dengan karyawan dan mempertimbangkan saran dari mereka.

4. Mempunyai orientasi prestasi artinya pemimpin ini menetapkan tujuan yang lebih menantang dan mengharapkan karyawan agar mempunyai prestasi pada tingkat tertinggi mereka.

Pemilihan gaya kepemimpinan yang tepat akan menyebabkan karyawan menjadi termotivasi untuk meraih prestasi yang lebih tinggi lagi, dengan tujuan perusahan akan dengan mudah tercapai. Kekompakan antara pimpinan dan karyawan juga akan menjadikan suasana tempat bekerja menjadi beriklim sejuk sehingga karyawan nyaman dalam bekerja.

Motivasi kerja merupakan suatu hal yang mendorong keinginan individu untuk melakukan kegiatankegiatan tertentu untuk mencapai keinginannya. Motivasi adalah pesti,mulasian kebutuhan yang berorientasi kepada tujuan individu dalam mencapai rasa puas.

(Sugiyono, 2015).

Selain itu motivasi kerja juga merupakan sesuatu yang menimbulkan dorongan atau semangat kerja yang dipengaruhi oleh beberapa faktor, antara lain atasan, sarana fisik, kebijaksanaan, peraturan, imbalan jasa uang dan non uang, jenis pekerjaan dan tantangan . (Lestari, 2018)

Ada lima dimensi motivasi kerja yaitu (Mangkunegara, 2013):

1. Fisiologis, yaitu kebutuhan akan makan, minum, perlindungan fisik, bernapas, dan sexual. Kebutuhan ini merupakan kebutuhan yang paling mendasar. Pemimpin perlu memberikan gaji yang layak kepada pegawai.

2. Rasa aman, yaitu kebutuhan perlindungan dari ancaman, bahaya, dan lingkungan kerja. Pemimpin perlu memberikan tunjangan kesehatan, asuransi kecelakaan, perumahan, dan dana pensiun.

3. Sosial atau rasa memiliki, yaitu kebutuhan untuk diterima dalam kelompok unit kerja, berafiliasi, berinteraksi, serta rasa dicintai dan mencintai. Pemimpin perlu menerima eksistensi/keberadaan pegawai sebagai anggota kelompok kerja, melakukan interaksi kerja yang baik, dan hubungan kerja yang harmonis.

4. Harga diri, yaitu kebutuhan untuk dihormati, dihargai oleh orang lain. Pemimpin tidak boleh sewenang-wenang memperlakukan pegawai karena mereka perlu dihormati, diberi penghargaan terhadap prestasi kerjanya.

Aktualisasi diri, yaitu kebutuhan untuk mengembangkan diri dan potensi, mengemukakan ide-ide, memberikan penilaian, kritik dan prestasi. Pemimpin perlu memberi kesempatan kepada pegawai bawahan agar merasa dapat mengaktulisasikan diri secara baik dan wajar di perusahaan.

\section{METODOLOGI PENELITIAN}

\section{Metode Penelitan}

Pada penelitian ini menggunakan metode penelitian kuantitatif deskriptif yaitu suatu metode penelitian yang berlandaskan terhadap filsafat positivisme, digunakan dalam meneliti terhadap sample dan pupulasi penelitian, tehnik pengambilan sample umunya dilakukan dengan acak atau random sampling, sedangkan pengumpulan data dilakukan dengan cara memanfaatkan instrumen penelitian yang dipakai, analisis data yang digunakan bersifat kuantitatif/bisa diukur dengan tujuan untuk menguji hipotesis yang ditetapkan sebelumnya (Sugiyono, 2015). 


\section{Populasi dan sampel}

Populasi dalam penelitian ini adalah seluruh karyawan yang bekerja di Bimbingan dan Konseling Belajar Nurul Fikri Ragunan Jakarta Selatan yang berjumlah 40 orang. Sampel yang diambil menggunakan metode sampel jenuh dimana seluruh populasi diambil sebagai sampel (Sugiyono, 2015)

3. Metode pengumpulan data

Adapun metode pengumpulan data pada penelitian ini dengan menyebarkan kuisioner yang berisi pertanyaan tertutup menggunakan skala Likert.

\section{Variabel Penelitian}

Penelitian ini menggunakan 2 variabel dengan variabel terikat (Y) adalah motivasi kerja dan variabel bebas (X) adalah gaya kepemimpinan.

Motivasi kerja adalah suatu alasan yang mendorong karyawan untuk bekerja di sebuah perusahaan. Sedangkan gaya kepemimpinan adalah pola menyeluruh dari tindakan seorang pemimpin baik yang tampak maupun yang tidak tampak oleh bawahannya

Dimensi dan indikator variabel gaya kepemimpinan bisa dilihat di tabel 1 berikut ini.

Tabel. 1 Dimensi dan Indikator Variabel Gaya Kepemimpinan

\begin{tabular}{|c|c|}
\hline Dimensi & Indikator \\
\hline 1. Direktif & $\begin{array}{l}\text { 1. Pemberian kesempatan kepada bawahannya untuk } \\
\text { mengetahui apa yang diharapkan untuk } \\
\text { dilakukannya,. } \\
\text { 2. Penjadwalan pekerjaan. } \\
\text { 3. Pemberian pedoman yang spesifik mengenai cara } \\
\text { menyelesaikan tugas. }\end{array}$ \\
\hline 2. Mendukung & $\begin{array}{l}\text { 4. Bersikap ramah kepada karyawan. } \\
\text { 5. Pemberian perhatian yang besar kepada karyawan. } \\
\text { 6. Penjaminan fasilitas penunjang dalam pelaksanaan } \\
\text { tugas karyawan. }\end{array}$ \\
\hline 3. Partisipatif & $\begin{array}{l}\text { 7. Selalu berkoordinasi dengan karyawan. } \\
\text { 8. Pertimbangkan saran karyawan sebelum } \\
\text { mengambil keputusan. }\end{array}$ \\
\hline $\begin{array}{l}\text { 4. Berorientasi } \\
\text { Prestasi }\end{array}$ & $\begin{array}{l}\text { 9. Penetapan serangkaian tujuan/target yang harus } \\
\text { dicapai karyawan. } \\
\text { 10. Mengharapkan karyawan mampu mengerjakan } \\
\text { serangkaian tujuan/target dengan hasil yang baik. }\end{array}$ \\
\hline
\end{tabular}

Adapun dan indikator untuk variabel Motivasi Kerja (Y) dapat dilihat pada tabel 2 berikut ini.

Tabel. 2 Dimensi dan Indikator Variabel Motivasi Kerja Karyawan

\begin{tabular}{|c|c|c|}
\hline & Dimensi & Indikator \\
\hline 1. & Kebutuhan fisiologis & $\begin{array}{l}\text { 1. Waktu istirahat yang diberikan cukup untuk } \\
\text { melaksanakan ibadah sholat, makan dan beristirahat. } \\
\text { 2. Jaminan sosial tenaga kerja dan tunjangan lainnya } \\
\text { telah dipenuhi oleh pihak kantor. }\end{array}$ \\
\hline 2. & $\begin{array}{l}\text { Kebutuhan akan } \\
\text { rasa aman }\end{array}$ & $\begin{array}{l}\text { 3. Telah memiliki sistem pengamanan dan pengawasan } \\
\text { yang baik } \\
\text { 4. Telah melengkapi karyawan dengan perlengkapan } \\
\text { perlindungan yang sesuai dengan standar keselamatan } \\
\text { kerja. }\end{array}$ \\
\hline 3. & Kebutuhan sosial & $\begin{array}{l}\text { 5. Seluruh karyawan selalu berusaha menciptakan, } \\
\text { mempertahan kan rasa kekeluargaan dan kerjasama } \\
\text { dalam lingkungan kerja. } \\
\text { 6. Bertukar pikiran dengan rekan kerja mengenai tugas } \\
\text { yang sedang dikerjakan bersama-sama. }\end{array}$ \\
\hline 4. & $\begin{array}{l}\text { Kebutuhan akan } \\
\text { harga diri }\end{array}$ & $\begin{array}{l}\text { 7. Penempatan pada posisi pekerjaan yang sesuai dengan } \\
\text { pendidikan dan keterampilan yang dimiliki. } \\
\text { 8. Atasan memberikan pujian maupun penghargaan } \\
\text { ketika tugas diselesaikan dengan baik. }\end{array}$ \\
\hline & $\begin{array}{l}\text { Kebutuhan } \\
\text { aktualisasi diri }\end{array}$ & $\begin{array}{l}\text { 9. Pihak kantor memberikan kesempatan untuk } \\
\text { mengembangkan potensi diri dengan memberikan } \\
\text { pelatihan. } \\
\text { 10. Pelatihan dan pendidikan yang diberikan selalu sesuai } \\
\text { dengan perkembangan ilmu pemgetahuan dan } \\
\text { teknologi. }\end{array}$ \\
\hline
\end{tabular}

Sumber: (Suwatno \& Priansa, 2014) 
5.Uji Validitas dan Reliabilitas

Uji Validitas merupakan suatu pengujian untuk melihat ketepatan data yang dikumpulkan oleh peneliti dalam setiap butirnya. Valid tidaknya suatu item instrumen dapat diketahui dengan membandingkan indeks korelasi product moment pearson dengan level of Significant 5\% terhadap nilai korelasinya. Bila signifikansi hasil korelasi lebih besar dari 0,05 maka dinyatakan valid dan sebaliknya dinyatakan tidak valid (Ghozali, 2016)

Adapun reliabilitas merupakan suatu pengujian dengan maksud melihat sejauh mana hasil pengukuran dengan menggunakan objek yang sama akan menghasilkan data yang sama (Sugiyono, 2015). Reliabilitas dalam penelitian ini menggunakan Cronbach's Alpha, dimana kuesioner dapat dikatakan reliabel jika nilai $\alpha>0,60$ (Ghozali, 2016)

6.Teknik Analisis Data
Teknik Analisis Data Analisis data dalam penelitian ini menggunakan deskriptif kuantitatif dengan teknik statitik uji normalitas, uji linearitas, analisis regresi linear sederhana, uji t, koefisien korelasi, dan koefisien determinasi. Teknik pengolahan data menggunakan program komputer SPSS versi 20.0

\section{HASIL DAN PEMBAHASAN}

1. Uji Validitas dan Reliabilitas

Uji validitas gaya kepemimpinan dalam penelitian ini dperoleh dengan memberikan 10 butir pertanyaan kepada responden dan setelah diolah didapat hasil seperti pada table 3. Begitu juga dengan uji validitas variable motivasi kerja karyawan juga diperoleh dengan memberikan 10 butir pertanyaan kepada responden yang hasil olah datanya dapat dilihat pada table 4 berikut ini.

\begin{tabular}{ccc}
\multicolumn{3}{c}{ Tabel 3. Hasil Uji Validitas } \\
Variabel Gaya Kepemimpinan $(\mathrm{X})$ \\
\hline No. Butir Instrumen & Koefisien & Keterangan \\
\hline 1 & 0,538 & Valid \\
2 & 0,504 & Valid \\
3 & 0,674 & Valid \\
4 & 0,780 & Valid \\
5 & 0,719 & Valid \\
6 & 0,578 & Valid \\
7 & 0,650 & Valid \\
8 & 0,392 & Valid \\
9 & 0,695 & Valid \\
10 & 0,588 & Valid \\
\hline
\end{tabular}

Sumber: Data yang diolah (2018)

Pada tabel 3 dapat dilihat bahwa semua butir pertanyaan pada variabel gaya kepemimpinan mempunyai koefien korelasi lebih besar dari 0,05 sehingga dapat disimpulkan bahwa semua butir pertanyaan tersebut valid

Tabel 4. Hasil Uji Validitas

Variabel Motivasi Kerja Karyawan (Y)

\begin{tabular}{ccc}
\hline No. Butir Instrumen & Koefisien & Keterangan \\
\hline 1 & 0,644 & Valid \\
2 & 0,755 & Valid \\
3 & 0,700 & Valid \\
4 & 0,644 & Valid \\
5 & 0,618 & Valid \\
6 & 0,710 & Valid \\
7 & 0,662 & Valid \\
8 & 0,661 & Valid \\
9 & 0,560 & Valid \\
10 & 0,509 & Valid \\
\hline
\end{tabular}

Sumber: Data yang diolah (2018)

Pada tabel 4 dapat dilihat bahwa semua butir pertanyaan pada variabel motivasi kerja karyawan mempunyai koefien korelasi lebih besar dari 0,05 sehingga dapat disimpulkan bahwa semua butir pertanyaan tersebut valid

Adapun hasil dari uji reliabilitas reliabilitas gaya kepemimpinan dengan rumus Cronbach's Alpha 2. Uji Normalitas diperoleh hasil 0,789 dimana 0,789 > 0,6, maka pertanyaan dari variabel gaya kepimpinan dinyatakan reliabel. Sedangkan hasil perhitumgan reliabilitas motivasi kerja karyawan diperoleh hasil 0,826, dimana $0,826>0,6$, maka pertanyaan dari variabel kinerja karyawan juga dinyatakan reliabel. 
Berdasarkan perhitungan uji normalitas dengan uji kolmogorov-smirnov dapat diketahui gaya kepemimpinan berdistribusi normal dengan nilai $\mathrm{p}=$ $0,281$ ( $p>0,05)$. Sedangkan kinerja karyawan juga berdistribusi normal.dengan nilai $\mathrm{p}=0,869$ ( $\mathrm{p}>$ $0,05)$. Berikut tabel yang menunjukkan tabel uji normalitas dengan One-Sample KolmogorovSmirnov Test

Tabel 5. Uji Normalitas

One-Sample Kolmogorov-Smirnov Test

\begin{tabular}{|c|c|c|c|}
\hline & & $\begin{array}{c}\text { Gaya } \\
\text { Kepemimpina } \\
n\end{array}$ & $\begin{array}{c}\text { Motivasi Kerja } \\
\text { Karyawan } \\
\end{array}$ \\
\hline \multirow[t]{2}{*}{$\mathrm{N}$} & & 30 & 30 \\
\hline & Mean & 42,07 & 42,93 \\
\hline \multicolumn{4}{|l|}{ Normal Parameters ${ }^{\mathrm{a}, \mathrm{b}}$} \\
\hline & Std. Deviation & 3,722 & 3,462 \\
\hline & Absolute & , 169 &, 117 \\
\hline \multirow[t]{2}{*}{ Most Extreme Differences } & Positive &, 169 &, 083 \\
\hline & Negative &,- 117 &,- 117 \\
\hline Kolmogorov-Smirnov Z & & ,971 &, 589 \\
\hline Asymp. Sig. (2-tailed) & & ,281 &, 869 \\
\hline \multicolumn{4}{|l|}{ a. Test distribution is Normal. } \\
\hline b. Calculated from data. & & & \\
\hline
\end{tabular}

Sumber: Data yang diolah (2018)

3.Uji Linearitas

Uji linearitas persamaan regresi diperoleh dari baris Deviation from Linearity yaitu $\mathrm{F}$ hitung $=0,810$, dengan nilai Sig $=0,622>0,05$. Hal ini dapat disimpulkan bahwa $\mathrm{H} 0$ diterima atau persamaan 4. Analisis Regresi Linear Sederhana.

Tujuan dilakukannya analisis regresi linear sederhana adalah untuk mengetahui pengaruh gaya kepemimpinan terhadap motivasi kerja karyawan. Berdasarkan tabel 7 diperoleh hasil bahwa konstanta regresi sebesar 13,363 dan koefesien variable $\mathrm{X}$ dalam hal ini adalah gaya kepemimpinan sebesar 0,657 maka persamaan regresi yang dibentuk adalah

$Y=13,363+0,657 X$

Hal ini dapat dirtikan jika gaya kepemimpinan sebesar 0 maka motivasi kerja karyawan Bimbingan Belajar dan Konsultasi Nurul Fikri Ragunan akan sebesar 13,363. Koefisien regresi gayakepemimpinan $=0,657$, menunjukkan bahwa adanya pengaruh positif antara gaya kepemimpinan dengan motivasi kerja karyawan di Bimbingan dan Konsultasi Belajar Nurul Fikri Ragunan. Hasil ini menunjukkan semakin tinggi gaya kepemimpinan akan diikuti dengan semakin tinggi motivasi kerja karyawan pada Bimbingan dan Konsultasi Belajar Nurul Fikri Ragunan.

5.Uji Hipotesis

Pengujian hipotesis pada penelitian ini bisa dilihat dari tabel 7, dimana tingkat signifikansi dari variabel gaya kepemimpinan diperoleh sebesar 0,00 yang regresi motivasi kerja karyawan atas gaya kepemimpinan adalah linear atau berupa garis lurus. Hasil perhitungan dari uji linearitas tersebut dapat diketahui dalam tabel 6 .

berarti dibawah 0,05 sehingga keputusan yang diambil adalah Ho ditolak dan H1 diterima. Artinya bahwa terdapat pengaruh yang signifikan anatara gaya kepemimpinan dengan motivasi kerja karyawan Bimbingan dan Konsultasi Belajar Nurul Fikri Ragunan. Dan hal ini sesuai dengan hasil penelitian terdahulu dari ketiga penelitian yang menyatakan bahwa ada pengaruh yang siginifikan antara gaya kepemimpinan dengan motivasi kerja (Syaiyid, Utami, \& Riza, 2013), (Rizqiyah et al., 2013)(Fauzen, 2014).

\section{Uji Determinasi}

Berdasarkan tabel 8 dapat diketahui bahwa nilai $\mathrm{R}$ square sebesar 0,568 atau $56,8 \%$ (dibulatkan) artinya pengaruh gaya kepemimpinan terhadap motivasi kerja sebanyak $56,8 \%$ dan sisanya $43,2 \%$ ditentukan faktor-faktor lain selain gaya kepemimpinan dan untuk mengetahuinya diperlukan penelitian lebih lanjut.

Berdasarkan score pada kuisioner, ditemukan bahwa gaya kepemimpinan yang paling banyak disukai oleh karyawan untuk memotivasi kerja karyawan pada Bimbingan dan Konsultasi Belajar Nurul Fikri Ragunan adalah gaya kepemimpinan yang mendukung dimana karyawan sangat menyukai pemimpin yang ramah dengan karyawan dan 
memberikan perhatian serta menjamin fasilitas penunjang yang mendukung dalam pelaksanaan tugas karyawan.

Tabel 6. Uji Linieritas

ANOVA Table

\begin{tabular}{|c|c|c|c|c|c|c|c|}
\hline & & & $\begin{array}{l}\text { Sum of } \\
\text { Square }\end{array}$ & Df & $\begin{array}{l}\text { Mean } \\
\text { Square }\end{array}$ & $\mathrm{F}$ & Sig \\
\hline Gaya & Between & (Combined) & 145,567 & 10 & 14,557 & 1,244 & 326 \\
\hline \multirow[t]{4}{*}{ Kepemimpinan } & Group & Linerarity & 61,136 & 1 & 61,136 & 5,225 &, 034 \\
\hline & & Deviation & 84,430 & 9 & 9,381 &, 810 & ,622 \\
\hline & & From & & & & & \\
\hline & & Linearity & & & & & \\
\hline \multirow{3}{*}{$\begin{array}{l}\text { Motivasi Kerja } \\
\text { Karyawan }\end{array}$} & Within & & 222,300 & 19 & 11,700 & & \\
\hline & Groups & & & & & & \\
\hline & Total & & 367,867 & 29 & & & \\
\hline
\end{tabular}

Sumber: Data yang diolah (2018)

Tabel 7.Hasil Analisis Regresi Linier Sederhana

\begin{tabular}{|c|c|c|c|c|c|c|}
\hline \multicolumn{7}{|c|}{ Coefficients $^{a}$} \\
\hline \multirow[b]{3}{*}{ Model } & & \multirow{2}{*}{\multicolumn{2}{|c|}{ Unstandardized Coefficients }} & \multirow{2}{*}{$\begin{array}{l}\text { Standardized } \\
\text { Coefficients }\end{array}$} & \multirow[b]{3}{*}{$t$} & \multirow[b]{3}{*}{ Sig. } \\
\hline & & & & & & \\
\hline & & $\mathrm{B}$ & Std. Error & Beta & & \\
\hline \multirow[t]{2}{*}{1} & (Constant) & 13,363 & 3,723 & & 3,590 &, 001 \\
\hline & Gaya Kepemimpinan & ,657 & ,093 & ,754 & 7,069 &, 000 \\
\hline a. Dep & dent Variable: Motivas & & & & & \\
\hline
\end{tabular}

Sumber: Data yang diolah (2018)

Tabel 8. Hasil Uji Determinasi

\begin{tabular}{llccc}
\hline \multicolumn{5}{c}{ Model Summary } \\
\hline Model & $R$ & $R$ Square & Adjusted $R$ & Std. Error of the \\
Square & Estimate \\
\hline 1 &, $754^{\text {a }}$ &, 568 &, 557 & 3,567 \\
\hline
\end{tabular}

a. Predictors: (Constant), Gaya Kepemimpinan

Sumber : Data yang diolah, 2018

\section{KESIMPULAN}

1.Hasil persamaan regresi dan pengujian menunjukkan pengaruh positif dan signifikan antara gaya kepemimpinan dengan motivasi kerja karyawan pada Bimbingan dan Konsultasi Belajar Nurul Fikri Ragunan Hasil ini bisa diartikan bahwa tinggi rendahnya motivasi kerja karyawan ditentukan oleh gaya kepemimpinan dari pemimpinan di Bimbingan dan Konsultasi Belajar Nurul Fikri Ragunan.

2.Hasil pengujian koefisien korelasi sebesar 0,754 menunjukkan hubungan yang cukup kuat antara gaya kepemimpinan dengan motivasi kerja karyawan pada Bimbingan dan Konsultasi Belajar Nurul Fikri Ragunan..

3. Koefisien determinasi menunjukkan kontribusi gaya kepemimpinan terhadap kinerja karyawan pada Bimbingan dan Konsultasi Belajar Nurul Fikri
Ragunan adalah 56,8 \%, sisanya 43,2\% dipengaruhi oleh faktor lain. Untuk itu perlu penelitian lebih lanjut diluar model yang dibahas dalam penelitian ini.

\section{REFERENSI}

Fauzen, A. (2014). ( studi pada karyawan AJB BUMIPUTERA kantor cabang celaket malang ). Jurnal Administrasi Bisnis (JAB), 9(2), 1-10. Retrieved from https://media.neliti.com/media/publications/71 707-ID-pengaruh-gaya-kepemimpinanterhadap-moti.pdf

Ghozali, I. (2016). Aplikasi Analisis Multivariete dengan Program IMB SPSS 23. Badan Penerbit Universitas Diponegoro. Semarang.

Kartono, \& Kartini. (2014). Pemimpin dan Kepemimpinan. Jakarta: PT Raja. Grafindo 
Persada.

Khairizah, A., Noor, I., Suprapto, A., Publik, J. A., Administrasi, F. I., \& Brawijaya, U. (2015). ( Studi pada Karyawan di Perpustakaan Universitas Brawijaya Malang ). Jurnal Administrasi Publik, 3(7), 1268-1272. Retrieved from http://administrasipublik.studentjournal.ub.ac.i d/index.php/jap/article/view/950/464

Lestari, N. E. P. (2018). Pengaruh Motivasi,Kompetensi, Kepemimpinan dan Lingkungan Kerja Terhadap Kinerja Karyawan Pada PT. Geotech Sistem Indonesia. Moneter, 5(1), 99-104.

Mangkunegara, A. P. (2013). Manajemen SDM Perusahaan. Bandung:. Bandung: PT Remaja Rosdakarya.

Muizu, W. O. Z., Irfan, M., \& Kaltum, U. (2017). Pengaruh Gaya Kepemimpinan Terhadap Kinerja Karyawan Deekey Shoes Garage. Junral Manajemen Bisnis Indonesia, 4, 272294. Retrieved from http://fmi.or.id/jmbi/index.php/jurnal/article/vi ew/124

Rizqiyah, I. A., Rahardjo, K., Utami, H. N., Administrasi, F. I., Brawijayamalang, U., Direktif, G. K., ... Karyawan, M. K. (2013). Pengaruh gaya kepemimpinan terhadap motivasi kerja karyawan. Jurnlal Administrasi Bisnis, 4 No 1, 1-10. Retrieved from http://administrasibisnis.studentjournal.ub.ac.i d/index.php/jab/article/view/154

Robbins, S. P., \& Judge, T. A. (2015). Organizational Behavior (16th ed.). United State America: Pearson Education Inc.

Sugiyono. (2015). Metode Penelitian Kuantitatif, kualitatif dan $R \& D$. Bandung: Alfabetha.

Suwatno, \& Priansa, D. J. (2014). Manajemen SDM dan Organisasi Publik dan Bisnis. Bandung: Alfabeta.

Syaiyid, E., Utami, H. N., \& Riza, M. F. (2013). PENGARUH GAYA KEPEMIMPINAN TERHADAP MOTIVASI KERJA (Studi Pada Karyawan Radar Malang PT. Malang Intermedia Pers). Jurnal Administrasi Bisnis
(JAB), 1(1), 104-113. Retrieved from http://administrasibisnis.studentjournal.ub.ac.i d/index.php/jab/article/view/16/1561

Tead, O. (2004). Budaya Organisasi dan Peningkatan Kinerja Perusahaan. Jakarta: PT Bumi Aksara.

\section{PROFIL PENULIS}

Wiwik Widayanti, SE.MM., Dilahirkan di Purworejo, 11 Mei 1977. Pada tahun 1995 -2001 menempuh pendidikan di jurusan Sosial Ekonomi Pertanian Universitas Pembangunan Nasional "Veteran" Yogyakarta dan pada tahun 2010-2012 melanjutkan pendidikan di jurusan Magister Manajemen Universitas BSI Bandung. Sejak tahun 2003 aktif sebagai pengajar di Akademi Sekretari dan Manajemen BSI Jakarta..

Isnurrini Hidayat Susilowati, SE.MM. lahir di Magelang Jawa Tengah menyelesaikan studi S1 di FE Universitas Sebelas Maret (UNS) Solo dan S2 Magister Manajemen di Institut Pertanian Bogor (IPB) Bogor. Pernah bekerja di PT.Bank Danamon Indonesia, Tbk Bone dan Pare-Pare Sulawesi Selatan sebagai Kepala Operasional dan Administrasi dan di PT. Bank Niaga, Tbk pada Divisi Marketing Komunikasi sebagai Koordinator Marketing Even. Saat ini aktif sebagai dosen pada AMIK BSI Bogor sejak tahun 2010 dan menjadi anggota konsorsium Akademi Manajemen Keuangan (AMK) BSI Jakarta.

Julia Retnowulan, SE.MM. Lahir di Medan 1975. Pada tahun 1994v- 1997 menempuh pendidikan di Politeknik Univesitas Indonesia jurusan Administrasi Niaga program studi Sektretaris, kemudian melanjutkan pendidikan di Jurusan Magister Manajemen Universitas Krisna Dwipayana. Pernah bekerja di perusahaan Trading Company sebagai sekretaris .Dan sejak tahun 2003 aktif sebagai pengajar di Akademi Sekretari dan manajemen BSI Jakarta

Iman Wahyudi , Amd, Lahir di Jakarta 1995 menempuh pendidikan di Akademi Bina Sarana Informatika jurusan Administrasi Bisnis kemudian sedang melanjutkan di Universitas Bina Sarana Informatika jurusan Administrasi Binsis 